\title{
Does recently invaded fall armyworm, Spodoptera frugiperda displace native lepidopteran pests of maize in India?
}

\author{
J. Divya ${ }^{1}$, C. M. Kalleshwaraswamy ${ }^{1, *}$, H. B. Mallikarjuna ${ }^{2}$ and \\ Sharanabasappa Deshmukh ${ }^{1}$ \\ ${ }^{1}$ Department of Agricultural Entomology, and \\ ${ }^{2}$ Department of Agricultural Statistics, University of Agricultural and Horticultural Sciences, Shivamogga 577204 , India
}

Competitions are common among interacting species for resources or space. In India, recently invaded fall armyworm (FAW), Spodoptera frugiperda (J. E. Smith) has to compete with native lepidopterans to become successful in an exotic environment. Invasive FAW and native pink stem borer (PSB), Sesamia inferens belong to the same feeding guild, and hence they are intraguild competitors. FAW is an aggressive pest and is known to have a cannibalism/predation habit and hence a good model system to study the ecological interactions. The present study examined the incidence of different lepidopteran pests in maize fields for three years after the recent invasion. Incidence of FAW increased over the years compared to other lepidopteran pests. Laboratory and field intraguild competition studies were conducted to understand the survival and fitness of FAW and PSB larvae under different competition scenarios. Our study demonstrated that survival of FAW was reduced in intraspecific as compared to interspecific competition. However, survival of PSB was significantly reduced in interspecific competition due to intraguild predation by FAW. Fitness cost analysis of PSB pupae survived in competition with FAW larvae indicated that they were negatively affected with reduced pupal weight. Low field incidence of PSB and its lowest survival in the presence of intraguild competitor, i.e. FAW prove that PSB might get displaced from the maize ecosystem in the near future.

Keywords: Fall armyworm, lepidopteran pests, intraguild competition, species displacement.

SPECIES displacement involves the removal of native species by an exotic species, or a previously established exotic by a newly introduced species. More than 100 displacement events have been enlisted involving insects and related arthropods ${ }^{1}$. In majority of the cases, exotic species had displaced the native species or previously established exotic species. Invasive species built-up rapidly and became predominant in the absence of their natural enemies and were able to displace the native spe-

\footnotetext{
*For correspondence. (e-mail: kalleshwaraswamycm@uahs.edu.in)
}

cies in a given habitat ${ }^{1}$. Generally invasive species have superior competitive ability compared to native species $^{2-6}$. Few examples of competitive displacement by an exotic species include displacement among stem borers, displacement of native Busseola fusca by an exotic Chilo partelluson maize in southern Africa ${ }^{7}$; the Mediterranean fruit fly Ceratitis capitata by an exotic fruit fly, Bactrocera dorsalis in Hawaii ${ }^{8}$, and Ceratitis cosyra by the invasive fruit fly Bactrocera invadens ${ }^{9}$.

Maize is one of the most widely grown crops having good adaptability under different agro-climatic scenarios. It is cultivated in nearly 150 Mha in about 160 countries. In India, maize is the third most important cereal crop after rice and wheat. However, various stress factors hinder maize production; insect pests are one among them. As many as 141 insect pests cause a varying degree of damage right from sowing till harvest ${ }^{10,11}$. Among the lepidopteran pests, spotted stem borer, C. partellus, pink stem borer (PSB), Sesamia inferens, oriental armyworm Mythimna seperata, maize cob borer Helicoverpa armigera, maize leaf folder Marasima trapezalis and tobacco caterpillar Spodoptera litura are common in India ${ }^{11}$.

Recently, an invasive polyphagous pest, fall armyworm (FAW), Spodoptera frugiperda was recorded for the first time on maize in Shivamogga, Karnataka ${ }^{12}$. Later, it was reported from different parts of the country ${ }^{13}$ and other parts of Asia ${ }^{14-17}$. Before the report of FAW on maize in India, the major lepidopteran pests infesting the crop were stem borers, $S$. inferens and C. partellus ${ }^{18-20}$, which are native to the country. These pests are known to attack all the aerial parts of the maize plant, viz. leaf whorl, stem, tassel, and cob, and cause parallel rows of oblong holes on leaves and dead hearts by boring into the stem ${ }^{21-23}$. Although considered as a leaf-feeding insect, FAW is known to attack other parts of the maize plant such as whorl, tassel and ear head ${ }^{24}$. The major symptoms caused are shot holes, skeletonized leaves and heavily windowed whorls with frass, and boring into the $\mathrm{cob}^{25,26}$

The competition for resources and space is an obvious phenomenon among intraguild feeders. PSB is prevalent in peninsular India ${ }^{27}$, and attacks the maize crop during early stage of growth to harvest, infesting cobs as well. 
RESEARCH ARTICLES

Table 1. Intra- and interspecific competition scenarios of Spodoptera frugiperda and Sesamia inferens involving different larval size*

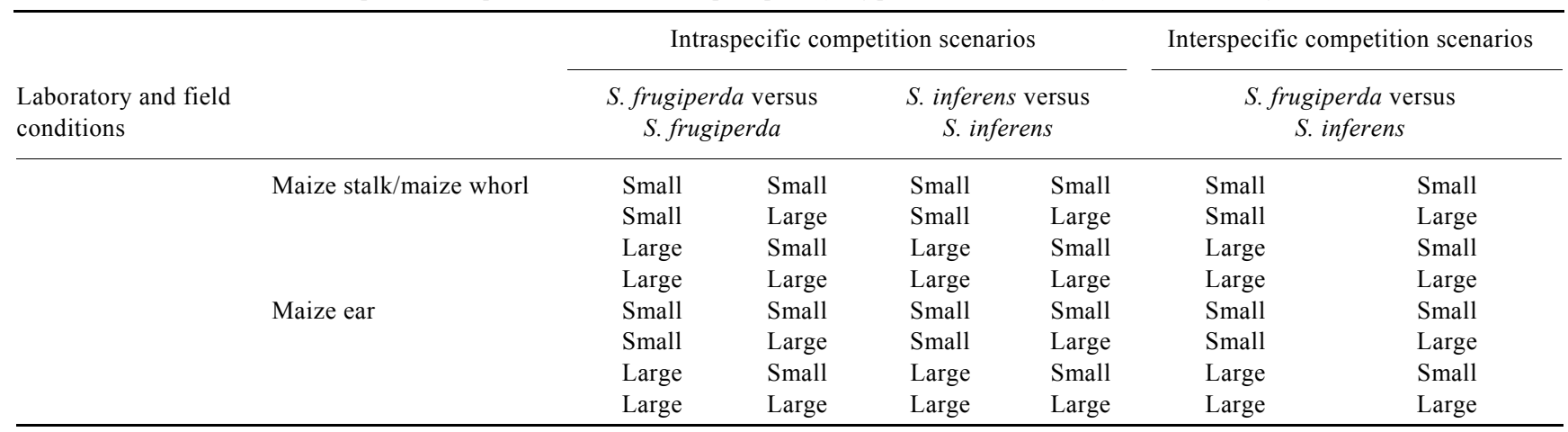

*Twenty-four competition scenarios (treatments) in 20 replications.

Similar to FAW, PSB remains in the whorl up to the third instar before boring into the $\operatorname{stem}^{28}$ and continue to occur in the cob where all developmental stages of both the species have to compete. Hence, FAW and PSB have identical ecological niche, i.e. both species belong to the same guild, thus competing for the same resource such as whorl/stalk and cob.

FAW is an aggressive pest known for its frequent cannibalistic behaviour ${ }^{29,30}$. It completes its lifecycle faster than PSB and is able to infest the crop earlier than the stem borer. Hence, the hypothesis is that the exotic FAW may displace the native PSB, S. inferens. So, knowledge of the pest scenario after its invasion and competitive displacements, if any, in the maize cropping system is required. The present study involves understanding the relative incidence of different lepidopteran pests in maize through a field survey for three consecutive years, intraguild competition studies and their effect on survival and fitness of two intraguild species, viz. FAW and PSB.

\section{Material and methods}

\section{Incidence of different lepidopteran pests in maize}

Roving survey was performed in the maize fields in four districts of Karnataka, viz. Shivamogga, Davanagere, Chikkamagaluru and Chitradurga which fall under two agroclimatic regions (central dry zone and southern transitional zone). Incidence of different lepidopteran pests was recorded during kharif season of 2018, 2019 and 2020. In each agro-climatic situation, a minimum of 25 maize fields were selected and surveyed. In each field, pest incidence was recorded by covering (walking) $5 \mathrm{~m}^{2}$ area in a zigzag manner in five spots. In each $5 \mathrm{~m}^{2}$ area walked, the total number of plants and the total number of plants damaged by different lepidopteran pests were noted down. Per cent incidence of each lepidopteran species was calculated based on symptoms produced ${ }^{12,21,22}$. In case it was difficult to observe the larvae in damaged plants, destructive sampling was done and species were noted down. In the field, if species could not be identified, specimens were collected, brought to the laboratory, reared until adult emergence and identified based on morphological characters and through dissection of male genitalia. In addition to maize, incidence of FAW was surveyed in sorghum, other millets, sugarcane and rice.

\section{Maintenance of laboratory culture of FAW and PSB}

The culture of FAW and PSB obtained from fieldcollected larvae or pupae was maintained at the Insect Systematics and Vector Biology Laboratory, College of Agriculture, University of Agricultural and Horticultural Sciences, Shivamogga. The larval culture was maintained in an insect growth chamber at $25^{\circ} \pm 1^{\circ} \mathrm{C}$, RH $80 \%$ and 14L : 10D using natural diet (maize stalk, maize ear from hybrid Pioneer 3550) for the supply of F1 larvae to the laboratory and field experiments.

\section{Intraguild competition}

The intraguild competition study was conducted using different intra- and interspecific competition scenarios among different larval instars of FAW and PSB (Table $1)$. The competition scenarios were performed on maize stalk and maize ear in the laboratory, and maize whorl and maize ear under field conditions. The competition scenarios were performed both in laboratory on maize stalk and maize ear and field conditions on maize whorl and ear during two the crop seasons of kharif and rabi 2019-20. Fitness cost analysis of survived larvae was determined to evaluate the effect of intraguild competition, cannibalism and predation on larval survival.

\section{Intraguild competition studies in the laboratory}

In the laboratory, the competition assays were performed on maize stalk and maize ear separately in transparent plastic rearing boxes. Maize stalks and maize ears were 
chopped into pieces $(5 \mathrm{~cm})$, precleaned with $1 \%$ sodium hypochlorite solution and then with distilled water, airdried and provided to the larvae. Sufficient quantity of maize stalk was provided and changed on a daily basis, whereas maize ear $(5 \mathrm{~cm})$ was changed on alternate days (as it was difficult to remove the larvae from the bored region and avoid interference in their growth).

Small (second instar; age group 3-6 days) and large (fourth to fifth instar; age group 6-9 days)-sized larvae (F1 generation) were selected for the competition experiment. Two larvae (same species in intraspecific competition scenarios and two larvae of different species in interspecific competition scenarios) were released into each plastic box containing maize stalk and maize ear separately according to the scenarios presented in Table 1. Each plastic box was considered as one replication and 20 such replications per scenario (a total of 20 scenarios/ treatment) were maintained for both maize stalk and maize ear in completely randomized design. The survival of larvae was assessed every day for ten days for the competition study on maize stalk. The survival of larvae on maize ear was assessed every alternate day while replenishing the diet.

Larvae of the same age as of those used in the competition scenarios (small and large) were reared individually on maize stalk and maize ear separately in the plastic containers. These individually reared larval data were used as control in the statistical analysis for fitness cost.

\section{Fitness cost evaluation}

Larvae that survived in different competition scenarios in a laboratory experiment on maize stalk and maize ear were reared with the same food until they reached the pupal stage. Individual pupae were kept in small plastic boxes. Pupal weight was determined using electric balance (ESSAE) two days after pupation in all the cases to avoid variation, and maintained until adult emergence to verify the pupal viability.

\section{Intraguild competition studies in the field}

Maize plants were raised in $25 \mathrm{~m}^{2}$ area in the field by sowing them (hybrid P3550 Pioneer) at a spacing of $60 \times 30 \mathrm{~cm}$. Plants were maintained healthy by application of the recommended quantity of fertigation and irrigation. Natural incidence, if any, was removed by handpicking insect stages and plants were made free of insect infestation.

For the study of intraguild competition on maize whorl, 20 plants (each of V10 stage; 30-35-day-old plants) were selected and two larvae were released into the whorl (based on the scenarios in Table 1). Individual plants were covered with a nylon net to avoid larval escape or parasitization/predation by natural enemies. Similarly, for the competition study on maize ear, 20 plants each of R3 stage (milky stage) were selected and larvae were released on maize ear. Individual maize ears were covered with a porous cloth bag to avoid larval escape. The survival of larvae was recorded ten days after manual infestation.

\section{Statistical analysis}

Incidence of different lepidopteran pests in different maize fields and regions were determined and expressed in percentage and compared. Data on larval survival from laboratory and field competition scenarios were assessed for normality using the Shapiro-Wilk test. The survival of larvae in different competition scenarios was tested using the chi-squared test $\left(\chi^{2} ; P \leq 0.05\right.$; SPSS v-20) between survival of the scenario and its corresponding control.

Observation on the pupal weight (a representative of fitness cost) was subjected to analysis of variance (ANOVA) after assessing for normality with ShapiroWilk test. When significant differences observed, Duncan's multiple range test (DMRT) $(P \leq 0.05)$ was used to compare the means of treatments.

\section{Results and discussion}

\section{Incidence of different lepidopteran pests}

Twenty-six, 164 and 47 fields were surveyed in the four districts during kharif 2018, 2019 and 2020 respectively. A total of six species of lepidopterans were found feeding on maize, viz. Spodoptera frugiperda, Spodoptera litura, Sesamia inferens, Chilo partellus, Mythimna separatae and Trichoplusia ni. The incidence of FAW was lowest compared to stem borers during 2018 (year of first report), while by the next two years (2019 and 2020) the incidence was highest among all other lepidopteran species.

During kharif 2018, incidence of FAW (2.13-6.73\%) was less compared to that of stem borers PSB (7.85$10.52 \%)$ and $C$. partellus (3.25-10.20\%). Incidence of $S$. litura and $M$. separatae ranged from $0.59 \%$ to $2.10 \%$ and $0 \%$ to $0.68 \%$ respectively (Figure $1 a$ ). However, during kharif 2019 and 2020, the average incidence of FAW ranged from $10.49 \%$ to $24.13 \%$ and $28.56 \%$ to $36.44 \%$ respectively (Figure $1 b$ and $c$ ). When the incidence of FAW and PSB was compared for three years, the incidence increased for FAW and decreased for PSB (Figure 2). There was $9.0 \%$ to $62.5 \%$ incidence of FAW during kharif, 2018 in different districts of Karnataka ${ }^{31}$. As high as 6.0-100\% FAW infestation was noticed in northern Karnataka during the year of pest invasion ${ }^{32}$. During the present study, it was also evident that FAW damage was mainly found on maize, especially up to 
50 days of crop growth. Negligible infestation was observed in a few sorghum fields, but not in rice, other millets and sugarcane as reported ${ }^{33-36}$. However, the highest incidence was mainly on maize (0-98\%), indicating the preference of FAW for maize over other crops which has more than 300 hosts $^{37}$.

Before the invasion of FAW in India, the predominant maize pests were stem borers $(S$. inferens and $C$. partellus $)^{38-40}$. Their incidence was prominent in Karnataka, with an average percentage infestation of 6.31-20.01 (ref. 41). The average percentage incidence of stem borers was 28.07-60.15 and 32.60-61.15 during kharif 2010-11 and 2011-12 respectively $^{41}$. During rabi $2010-11$ and $2011-$ 12 , it ranged from $31.30 \%$ to $67.07 \%$ and $32.48 \%$ to $66.39 \%$ respectively ${ }^{42}$. Results of this study show that the incidence of stem borers had reduced to a greater extent compared to earlier years due to invasion of FAW. Our preliminary studies (data not shown) also indicate high incidence of PSB in rabi, sorghum and rice fields, which were not known to be seriously infested by this stem borer, indicating the possible host shift by native PSB S. inferens.
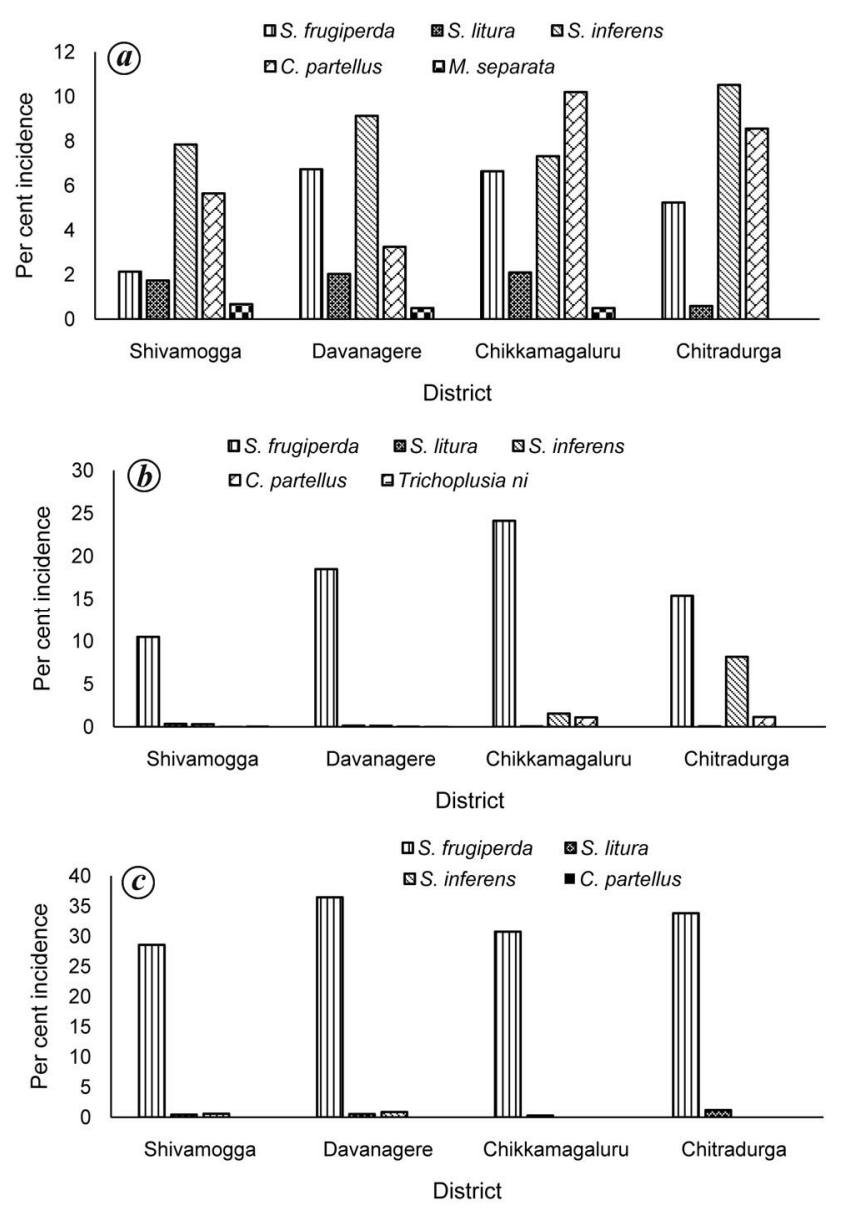

Figure 1. Incidence of different lepidopteran pests maize in four major maize-growing districts of Karnataka, India during kharif: $\boldsymbol{a}, 2018 ; \boldsymbol{b}, 2019 ; \boldsymbol{c}, 2020$.

\section{Intraguild competition studies in the laboratory}

Survival of FAW was significantly lower in intraspecific competition than in competition with PSB (interspecific) on maize stalk (Table 2). Survival was $85.71 \%$ and 94.11\% when small FAW larvae competed with the small and large PSB larvae respectively. Whereas FAW had $94.11 \%$ and $100 \%$ survival in the competition scenarios of large versus small and large versus large PSB respectively. In intraspecific competition scenarios, the survival of small versus small and small versus large FAW larvae was significantly lower at $53.33 \%$ and $51.85 \%$ respectively. Similarly, survival was $74.01 \%$ and $64.71 \%$ in the competition scenarios of large versus small and large versus large FAW larvae respectively.

On maize ear, the survival of FAW was significantly higher in small versus small PSB larvae (95.65\%) $(P=$ $\left.0.0039, \chi^{2}=8.30, \mathrm{~d} f=1\right)$. Survival was $100 \%$ when small FAW competed with a large congeneric competitor (PSB) $\left(P=<0.0001, \chi^{2}=20.12, \mathrm{~d} f=1\right)$. However, the survival of FAW in large versus small and large versus large with PSB did not differ significantly from the intraspecific competition (Table 2). Survival of FAW was $66.67 \%$ when two small conspecific larvae competed with each other. Significantly lower survival of small FAW larvae (45\%) was observed against large conspecific competitor.

The survival of PSB in competition with FAW (interspecific competition) was significantly lower than the intraspecific competition for all the competition scenarios $(P \leq 0.01)$ on maize stalk and maize ear (Table 3$)$. When small PSB competed with small FAW on maize stalk, the survival was $0 \%$ and with large FAW, the survival was $23.50 \%$. Survival of PSB against FAW was $17.65 \%$ and $11.76 \%$ when large PSB competed with small and large FAW respectively. This indicates that longer the larvae are in competition and faster growth rate of $S$. frugiperda

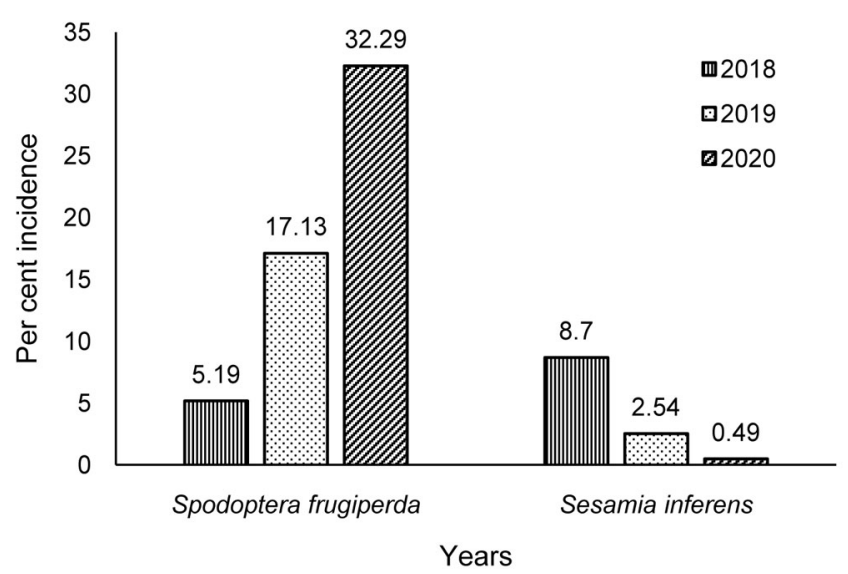

Figure 2. Incidence of Spodoptera frugiperda and Sesamia inferens over a period of three years. 
RESEARCH ARTICLES

Table 2. Survival of S. frugiperda larvae in intra- and interspecific competition in maize stalk and maize ear under laboratory and field

\begin{tabular}{|c|c|c|c|c|c|c|c|c|}
\hline \multirow[b]{2}{*}{ Site } & \multicolumn{2}{|c|}{ Competition } & \multicolumn{2}{|c|}{$\begin{array}{l}\text { Survival of } S \text {. frugiperda } \\
\text { versus } S \text {. frugiperda }\end{array}$} & \multicolumn{2}{|c|}{$\begin{array}{l}\text { Survival of } S \text {. frugiperda } \\
\text { versus } S \text {. inferens }\end{array}$} & \multirow[b]{2}{*}{$\chi^{2}$} & \multirow[b]{2}{*}{$P$-value } \\
\hline & S. frugiperda & Competitor & Live larvae & Per cent & Live larvae & Per cent & & \\
\hline \multicolumn{9}{|l|}{ Laboratory } \\
\hline \multirow[t]{4}{*}{ Maize stalk } & Small & Small & $8(15)^{\#}$ & 53.33 & $18(21)^{\#}$ & 85.71 & $6.33 *$ & 0.0119 \\
\hline & Small & Large & $14(27)$ & 51.85 & $16(17)$ & 94.11 & $10.65 * *$ & 0.0011 \\
\hline & Large & Small & $20(27)$ & 74.07 & $16(17)$ & 94.11 & $4.33^{*}$ & 0.0375 \\
\hline & Large & Large & 11(17) & 64.71 & $17(17)$ & 100.00 & $9.92 * *$ & 0.0016 \\
\hline \multirow[t]{4}{*}{ Maize ear } & Small & Small & $14(21)$ & 66.67 & $22(23)$ & 95.65 & $8.30 * *$ & 0.0039 \\
\hline & Small & Large & $8(20)$ & 45.00 & $20(20)$ & 100.00 & $20.12 * *$ & $<0.0001$ \\
\hline & Large & Small & $20(20)$ & 100.00 & $17(18)$ & 94.44 & $0.002^{\mathrm{NS}}$ & 0.9574 \\
\hline & Large & Large & $17(20)$ & 85.00 & $22(23)$ & 95.65 & $2.98^{\mathrm{NS}}$ & 0.0844 \\
\hline \multicolumn{9}{|l|}{ Field } \\
\hline \multirow[t]{4}{*}{ Maize whorl } & Small & Small & $8(15)$ & 53.33 & $20(20)$ & 100.00 & $14.77 * *$ & 0.0001 \\
\hline & Small & Large & $6(15)$ & 40.00 & $18(20)$ & 90.00 & $12.40 * *$ & 0.0004 \\
\hline & Large & Small & $13(15)$ & 86.67 & $19(20)$ & 95.00 & $2.20^{\mathrm{NS}}$ & 0.1385 \\
\hline & Large & Large & $14(15)$ & 93.33 & $15(15)$ & 100.00 & $4.14^{*}$ & 0.0419 \\
\hline \multirow[t]{4}{*}{ Maize ear } & Small & Small & $12(15)$ & 80.00 & $15(15)$ & 100.00 & $5.93 *$ & 0.0149 \\
\hline & Small & Large & $10(15)$ & 66.67 & $14(15)$ & 93.33 & $5.21 *$ & 0.0225 \\
\hline & Large & Small & $15(15)$ & 100.00 & $15(15)$ & 100.00 & - & - \\
\hline & Large & Large & $13(15)$ & 86.67 & $15(15)$ & 100.00 & $4.82 *$ & 0.0281 \\
\hline
\end{tabular}

"Values in parenthesis represent total number of insects examined.

* Significant at $P \leq 0.05 ; * *$ Significant at $P \leq 0.01$; NS, Non significant at $P>0.05$.

Table 3. Survival of $S$. inferens larvae in intra- and interspecific competition in maize stalk and maize ear under laboratory and field

\begin{tabular}{|c|c|c|c|c|c|c|c|c|}
\hline \multirow[b]{2}{*}{ Site } & \multicolumn{2}{|c|}{ Competition } & \multicolumn{2}{|c|}{$\begin{array}{l}\text { Survival of } S \text {. inferens } \\
\text { versus } S . \text { inferens }\end{array}$} & \multicolumn{2}{|c|}{$\begin{array}{l}\text { Survival of } S \text {. inferens } \\
\text { versus } S \text {. frugiperda }\end{array}$} & \multirow[b]{2}{*}{$\chi^{2}$} & \multirow[b]{2}{*}{$P$-value } \\
\hline & S. inferens & Competitor & Live larvae & Percent & Live larvae & Percent & & \\
\hline \multicolumn{9}{|l|}{ Laboratory } \\
\hline \multirow[t]{4}{*}{ Maize stalk } & Small & Small & $17(20)^{\#}$ & 85 & $0(21)^{\#}$ & 0.00 & $27.09 * *$ & $<0.0001$ \\
\hline & Small & Large & $18(20)$ & 90 & $4(17)$ & 23.50 & $14.20 * *$ & 0.0002 \\
\hline & Large & Small & $20(20)$ & 100 & $3(17)$ & 17.65 & $23.11 * *$ & $<0.0001$ \\
\hline & Large & Large & $18(18)$ & 100 & $2(17)$ & 11.76 & $24.31 * *$ & $<0.0001$ \\
\hline \multirow[t]{4}{*}{ Maize ear } & Small & Small & $20(20)$ & 100 & $5(23)$ & 21.74 & $23.80 * *$ & $<0.0001$ \\
\hline & Small & Large & $19(20)$ & 95 & $9(20)$ & 45.00 & $9.64 * *$ & 0.0019 \\
\hline & Large & Small & $20(20)$ & 100 & $10(18)$ & 55.00 & $8.74 * *$ & 0.0031 \\
\hline & Large & Large & $20(20)$ & 100 & $7(23)$ & 30.43 & $19.28 * *$ & $<0.0001$ \\
\hline \multicolumn{9}{|l|}{ Field } \\
\hline \multirow[t]{4}{*}{ Maize whorl } & Small & Small & $20(20)$ & 100 & $6(20)$ & 30.00 & $18.57 * *$ & $<0.0001$ \\
\hline & Small & Large & $18(20)$ & 90 & $5(20)$ & 35.00 & $10.67 * *$ & 0.0011 \\
\hline & Large & Small & $20(20)$ & 100 & $7(20)$ & 50.00 & $10.80 * *$ & 0.0010 \\
\hline & Large & Large & $20(20)$ & 100 & $8(15)$ & 53.33 & $8.93 * *$ & 0.0028 \\
\hline \multirow[t]{4}{*}{ Maize ear } & Small & Small & $15(15)$ & 100 & $4(15)$ & 26.67 & $14.35 * *$ & 0.0001 \\
\hline & Small & Large & $15(15)$ & 100 & $8(15)$ & 33.33 & $12.15 * *$ & 0.0005 \\
\hline & Large & Small & $15(15)$ & 100 & $7(15)$ & 46.67 & $8.35 * *$ & 0.0039 \\
\hline & Large & Large & $15(15)$ & 100 & $9(15)$ & 60.00 & $5.21 * *$ & 0.0225 \\
\hline
\end{tabular}

${ }^{\#}$ Values in parentheses represent total number of larvae examined; **Significant at $P \leq 0.01$.

result in aggressive attack and feeding on the competitor. In intraspecific competition, the survival of small versus small and small versus Large PSB was $85 \%$ and $90 \%$ respectively. Whereas there was $100 \%$ survival of PSB in intraspecific competition scenarios involving large versus large and large versus small.

Significantly lower survival of PSB in all competition scenarios against FAW on maize ear was observed (Table
3). Survival of small PSB larvae in competition with small and large FAW larvae was $21.74 \%$ and $45 \%$ respectively. Survival of large PSB reached up to $55 \%$ and $30.43 \%$ against small and large FAW respectively. In conspecific competition scenarios the survival of PSB was $100 \%$, except for the scenario involving small versus large, where survival of small PSB larvae was $95 \%$ (Table 3). 


\section{Intraguild competition studies in the field}

On maize whorl, there was no significant difference in survival of FAW between inter- and intraspecific competition scenario of large versus small larvae $(P=0.1385$, $\chi^{2}=2.20, \mathrm{~d} f=1$, Table 2). In the competition scenario of small versus small and large versus large, FAW survival was $100 \%$ against PSB. While in intraspecific competition, the survival was $53.33 \%$ and $93.33 \%$ in the small versus small and large versus large scenarios respectively. Survival of small FAW larvae remained high against large PSB larvae $(90 \%)$ and low in the conspecific competition $(40 \%)$ involving small versus large larvae $\left(P<0.0001, \chi^{2}=12.40, \mathrm{~d} f=1\right)$.

On maize ear, survival of FAW was significantly higher in congeneric competition than in conspecific competition, except for the scenario of large versus small larvae, where survival of FAW did not differ significantly between inter- and intraspecific competition (Table 2). The survival of FAW against PSB was $93.33 \%$ in the competition scenario of small versus large, but it was $100 \%$ for small versus small and large versus large respectively. In intraspecific competition scenarios, survival of FAW was $80 \%, 66.67 \%$ and $86.67 \%$ in the scenarios of small versus small, small versus large and large versus large respectively.

Intraguild competition on maize whorl indicated significant lower survival of PSB in all competition scenarios (Table 3). Survival of PSB in the scenarios of small versus small and small versus large FAW larvae was 30\% and $35 \%$ respectively. PSB survived up to $50 \%$ and $53.33 \%$ when large larvae competed with small and large FAW larvae respectively. In conspecific competition scenarios, PSB survival reached $100 \%$, except with the scenario small versus large, where the survival was $90 \%$.

Similarly, on maize ear the survival of PSB was $100 \%$ in all the conspecific competition scenarios. In all the congeneric competition scenarios, the survival of PSB against FAW was significantly reduced. Survival of small and large PSB larvae against a large competitor (FAW) was $33.33 \%$ and $60 \%$ respectively. Survival of small and large PSB larvae was $26.67 \%$ and $46.67 \%$ respectively, against small congeneric (FAW) competitor larvae (Table 3).

Both laboratory and field studies indicated that under asymmetric size interactions, i.e. large versus small and small versus large, the survival of small FAW larvae was significantly reduced, while that of large FAW larvae was significantly higher. So, large larvae gain survival advantage in intraspecific competition. This may be due to higher attacking movements ${ }^{43}$ and high rate of cannibalism in later instars of FAW even when the food is not scarce $^{44}$. It has also been demonstrated that FAW is an aggressive species and frequency of cannibalism is directly proportional to age ${ }^{44}$. Similarly, cannibalism and aggressiveness of Helicoverpa zea increase with age ${ }^{45}$.
The success of large-sized larvae over small-sized ones is due to reduced risks associated with the attack of smaller instars $^{46}$, thus gaining competitive advantage.

The survival of FAW was relatively higher on maize ear than on maize stalk under both laboratory and field intraguild competition trials. This might be due to the greater quantity and quality of diet in maize ear than maize stalk; the frequency of encounter by competitor larvae was less due to the larger area for escape. Previous competition experiments among three noctuid pests $(S$. frugiperda with Striacosta albicosta and H. zea) have indicated that survival of $S$. albicosta was highest on maize ears than on maize silk due to greater quality and quantity of food and bigger surface area of maize $\mathrm{ear}^{47}$. On maize ear, survival of large FAW larvae was highest irrespective of the size of the competitor. Whereas survival of small versus small competitor and small versus large competitor was significantly lower. Hence more than one large-sized FAW larva usually does not cohabit the same whorl, but several small-sized larvae have been found feeding on the same whor ${ }^{47}$. The results have ecological information indicating that if a larva of FAW is already inhabiting the maize whorl, it is difficult for the larvae of another species to attack and enter into its competitor niche.

In conspecific competition scenarios the survival of PSB was almost $100 \%$ except in the scenario of small versus small $(85 \%)$ and small versus large $(95 \%$ and $90 \%$ ) wherein only $10 \%-15 \%$ mortality was observed. This is attributed to natural mortality. Thus, PSB larval survival was highest in intraspecific competition than interspecific competition. Therefore, several PSB larvae were found feeding on the same plant in the field. When two different species share the same food resource, cannibalism and intraguild predation are a common phenomenon $^{48}$. Results of the present study clearly indicate that PSB is devoured by the competitor FAW. As a result, survival is highly affected in interspecific competition. Such predation by large-sized S. frugiperda on $H$. zea and S. albicosta has been reported ${ }^{47}$. Cannibalism and intraguild predation confer an advantage to cannibals through the elimination of potential competitors from its niche, which results in greater availability of food ${ }^{48}$. In addition, variation in the developmental period confers advantages to FAW. The developmental period of PSB (23-39 days $)^{49-51}$ was higher compared to FAW (14-21 days) ${ }^{52}$. Undoubtedly, this slower development of PSB may help the competitor gain advantage in terms of food and space. Another possibility could be the time of habitat occupation. The egg-laying of FAW starts from the two-leaf stage (7-10-day-old seedlings) and stem borer incidence usually starts from the second to third week after sowing. This could be another reason for its competitive displacing ability wherein the first inhabitant with a faster growth rate has a defensive advantage over the much younger larvae of PSB. 
Table 4. Mean ( \pm SE of mean) of pupal weight of $S$. frugiperda developed in different competition scenarios beginning from small to large-sized larvae on maize stalk

\begin{tabular}{|c|c|c|c|c|c|}
\hline \multicolumn{2}{|c|}{ Competition scenario } & \multicolumn{2}{|r|}{ Male } & \multicolumn{2}{|c|}{ Female } \\
\hline Species & Competitor species & $n$ & Pupal weight (mg) & $n$ & Pupal weight (mg) \\
\hline \multirow[t]{6}{*}{ S. frugiperda (small) } & S. frugiperda (small) & 8 & $156.25 \pm 11.07^{\mathrm{d}}$ & 5 & $169.80 \pm 17.02$ \\
\hline & S. frugiperda (large) & 6 & $204.33 \pm 8.33^{\mathrm{ab}}$ & 4 & $188.25 \pm 24.33$ \\
\hline & S. inferens (small) & 8 & $180.25 \pm 7.69^{c}$ & 9 & $191.56 \pm 10.70$ \\
\hline & S. inferens (large) & 7 & $183.86 \pm 5.55^{\mathrm{bc}}$ & 6 & $155.00 \pm 9.57$ \\
\hline & Control & 12 & $211.58 \pm 9.44^{\mathrm{a}}$ & 12 & $194.00 \pm 7.86$ \\
\hline & $P$-value & & 0.001 & & 0.138 \\
\hline \multirow[t]{6}{*}{ S. frugiperda (large) } & S. frugiperda (small) & 4 & $215.25 \pm 15.00^{\mathrm{a}}$ & 9 & $186.11 \pm 9.04^{\mathrm{a}}$ \\
\hline & S. frugiperda (large) & 5 & $152.60 \pm 19.93^{b}$ & 7 & $156.71 \pm 11.99^{\mathrm{b}}$ \\
\hline & S. inferens (small) & 5 & $201.20 \pm 5.46^{\mathrm{a}}$ & 4 & $202.75 \pm 5.20^{\mathrm{a}}$ \\
\hline & S. inferens (large) & 4 & $207.75 \pm 15.37^{\mathrm{a}}$ & 7 & $195.00 \pm 8.94^{\mathrm{a}}$ \\
\hline & Control & 10 & $204.00 \pm 10.64^{\mathrm{a}}$ & 10 & $203.70 \pm 12.41^{\mathrm{a}}$ \\
\hline & $P$-value & & 0.044 & & 0.039 \\
\hline
\end{tabular}

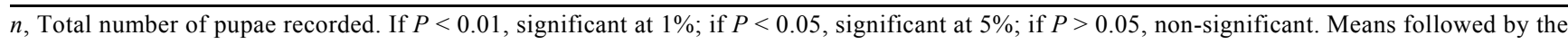
same letter do not differ by DMRT.

\section{Fitness cost studies}

A significant difference was observed in the pupal weight of male FAW that survived from competition and control, when small larvae were reared on maize stalk $(F=6.01$; $\mathrm{d} f=4,36 ; P=0.001$; Table 4). Pupal weight of male FAW reared individually on maize stalk $(211.58 \mathrm{mg})$ was significantly greater than that of small larvae surviving in different competition scenarios. Significantly lowest male pupal weight (156.25 mg) was observed when two small larvae of FAW competed with each other. However, there was no significant difference in pupal weight between small competing and non-competing female FAW reared on maize stalk $(F=1.88 ; \mathrm{d} f=4,31 ; P=0.138$; Table 4$)$.

Male pupal weight of large FAW larvae that survived in competition with small conspecific larvae $(215.25 \mathrm{mg})$ was significantly greater. Significantly lowest male pupal weight $(152.60 \mathrm{mg})$ was observed when two larger conspecific larvae of FAW competed with each other. There was no marked difference in male pupal weight of large FAW larvae that survived in competition with PSB (large versus small - $201.20 \mathrm{mg}$ and large versus large $207.75 \mathrm{mg}$ ). Male pupal weight of large FAW larvae not in competition with other larvae $(204.00 \mathrm{mg})$ was also greater (Table 4).

Pupal weight of female FAW reared individually from large larvae $(203.70 \mathrm{mg})$ was significantly greater than the pupal weight of large larvae that survived from different competition scenarios $(F=2.86 ; \mathrm{d} f=4, \quad 32$; $P=0.039$; Table 4).

Pupal weight of FAW (both male and female) did not differ significantly among competing and non-competing larvae that survived from different competition scenarios and control on maize ear (Table 5).

Pupal weight of PSB did not differ significantly between competing and non-competing larvae surviving competition as small males $(F=2.86 ; \mathrm{d} f=4,32 ; P=$ $0.146)$ or large males $(F=0.04 ; \mathrm{d} f=4,27 ; P=0.997$; Table 6) on maize stalk. However, significant difference was observed in female pupal weight of both large and small PSB between competition scenarios and control (Table 6). Pupal weight of female PSB reared individually on maize stalk (191.92 mg) was significantly greater than that of large competing larvae $(F=2.69 ; \mathrm{d} f=4,29$; $P=0.044)$. Whereas the lowest female pupal weight (130.00 mg) was recorded for large PSB larvae which competed against large FAW larvae.

Male pupal weight of PSB significantly differed among different competition scenarios and control, when small PSB larvae competed in various competition scenarios $(F=3.49 ; \mathrm{d} f=4,29 ; P=0.019 ;$ Table 7$)$. Significantly greater pupal weight of male PSB (150.69 mg) was observed for non-competing larvae and the lowest pupal weight $(107.50 \mathrm{mg})$ for small versus small FAW larvae.

Results of the pupal weight of male PSB reared from large larvae on maize ear revealed statistically significant difference between control and competition scenarios $(F=4.34 ; \mathrm{d} f=4,32 ; P=0.006$ (Table 7$))$. Pupal weight of male PSB $(148.75 \mathrm{mg})$ reared individually on maize ear was significantly greater than that of large larvae that survived in competition. Female pupal weight of large PSB did not differ significantly among inter and intraspecific competition scenarios and control $(F=0.35 ; \mathrm{d} f=4$, 33; $P=0.836$; Table 7).

The larvae engaged in cannibalism had lower pupal weight and reduced fitness in the case of $\mathrm{FAW}^{47}$. Interestingly, pupal weight of FAW did not differ from control and competition scenarios, when larvae were reared and allowed for competition on maize ear. This might be due to compensation of competition effect by higher-quality food from maize ear. Therefore, only under limited food 
RESEARCH ARTICLES

Table 5. Mean ( \pm SE of mean) of pupal weight of $S$. frugiperda developed in different competition scenarios beginning from small to large-sized larvae on maize ear

\begin{tabular}{|c|c|c|c|c|c|}
\hline \multicolumn{2}{|c|}{ Competition scenario } & \multicolumn{2}{|c|}{ Male } & \multicolumn{2}{|c|}{ Female } \\
\hline Species & Competitor species & $n$ & Pupal weight (mg) & $n$ & Pupal weight (mg) \\
\hline \multirow[t]{6}{*}{ S. frugiperda (small) } & S. frugiperda (small) & 7 & $219.57 \pm 9.54$ & 11 & $209.27 \pm 11.83$ \\
\hline & S. frugiperda (large) & 4 & $194.75 \pm 23.76$ & 4 & $189.50 \pm 16.19$ \\
\hline & S. inferens (small) & 9 & $211.00 \pm 8.57$ & 9 & $188.00 \pm 3.86$ \\
\hline & S. inferens (large) & 6 & $195.50 \pm 4.88$ & 6 & $185.33 \pm 10.11$ \\
\hline & Control & 8 & $209.75 \pm 15.63$ & 12 & $198.58 \pm 11.75$ \\
\hline & $P$-value & & 0.637 & & 0.547 \\
\hline \multirow[t]{6}{*}{ S. frugiperda (large) } & S. frugiperda (small) & 7 & $196.29 \pm 5.26$ & 10 & $189.30 \pm 8.67$ \\
\hline & S. frugiperda (large) & 9 & $193.00 \pm 6.22$ & 11 & $179.36 \pm 6.37$ \\
\hline & S. inferens (small) & 10 & $202.40 \pm 8.17$ & 6 & $205.33 \pm 9.37$ \\
\hline & S. inferens (large) & 11 & $214.45 \pm 13.76$ & 9 & $218.11 \pm 15.03$ \\
\hline & Control & 10 & $192.30 \pm 5.63$ & 10 & $188.10 \pm 13.79$ \\
\hline & $P$-value & & 0.376 & & 0.123 \\
\hline
\end{tabular}

$\bar{n}$, Total number of pupae recorded. If $P<0.01$, significant at $1 \%$; if $P<0.05$, significant at $5 \%$; if $P>0.05$, non-significant. Means followed by the same letter do not differ by DMRT.

Table 6. Mean ( \pm SE of mean) of pupal weight of $S$. inferens developed in different competition scenarios beginning from small to large-sized larvae on maize stalk

\begin{tabular}{|c|c|c|c|c|c|}
\hline \multicolumn{2}{|c|}{ Competition scenario } & \multicolumn{2}{|l|}{ Male } & \multicolumn{2}{|l|}{ Female } \\
\hline Species & Competitor species & $n$ & Pupal weight (mg) & $n$ & Pupal weight (mg) \\
\hline \multirow[t]{6}{*}{ S. inferens (small) } & S. inferens (small) & 8 & $94.25 \pm 3.75$ & 8 & $121.38 \pm 16.53$ \\
\hline & S. inferens (large) & 12 & $98.83 \pm 4.22$ & 3 & $101.67 \pm 3.76$ \\
\hline & S. frugiperda (small) & - & - & - & - \\
\hline & S. frugiperda (large) & 2 & $82.50 \pm 12.50$ & 2 & $200.00 \pm 25.00$ \\
\hline & Control & 10 & $106.30 \pm 3.51$ & 10 & $152.50 \pm 6.81$ \\
\hline & $P$-value & & 0.146 & & 0.029 \\
\hline \multirow[t]{6}{*}{ S. inferens (large) } & S. inferens (small) & 9 & $107.33 \pm 5.40$ & 10 & $153.20 \pm 14.92^{\mathrm{b}}$ \\
\hline & S. inferens (large) & 10 & $111.20 \pm 10.21$ & 8 & $142.75 \pm 15.45^{\mathrm{b}}$ \\
\hline & S. frugiperda (small) & 1 & $107.00 \pm 00.00$ & 2 & $144.00 \pm 11.00^{\mathrm{b}}$ \\
\hline & S. frugiperda (large) & - & - & 2 & $130.00 \pm 5.00^{c}$ \\
\hline & Control & 12 & $108.58 \pm 3.26$ & 12 & $191.92 \pm 8.99^{\mathrm{a}}$ \\
\hline & $P$-value & 0.997 & & 0.044 & \\
\hline
\end{tabular}

$\bar{n}$, Total number of pupae recorded. If $P<0.01$, significant at $1 \%$; if $P<0.05$, significant at $5 \%$; if $P>0.05$, non-significant. Means followed by the same letter do not differ by DMRT.

condition, cannibalism and intraguild predation benefitted an individual in terms of increased body mass, increased rate of development and fecundity ${ }^{53}$. Overall, the fitness study advocates that larvae that survived in competition with FAW were negatively affected with reduced pupal weight.

\section{Conclusion}

This study clearly indicates that the incidence of PSB was significantly reduced after invasion of FAW. In support to this, the survival of PSB was also greatly reduced and negatively affected when in competition against FAW. As these two species are intraguild competitors, there will be competition for resource utilization leading to displacement of a weaker competitor, or both species may survive by acquiring the resource at different stages of the crop. In the near future, several ecological consequences can be expected due to invasion of FAW. These include host shift of native lepidopterans, host part shift and seasonal variation in occurrence. In this context, competition for resource utilization, cannibalistic nature and intraguild predation nature of FAW are the main factors for the reduction of stem borer incidence and its displacement from the maize ecosystem. The ecological consequences of competition such as host shift and niche partitioning need further studies. Complete monitoring of the incidence of FAW and other lepidopteran pests in a range of 


\section{RESEARCH ARTICLES}

Table 7. Mean ( \pm SE of mean) of pupal weight of $S$. inferens developed in different competition scenarios beginning from small to large-sized larvae on maize ear

\begin{tabular}{|c|c|c|c|c|c|}
\hline \multicolumn{2}{|c|}{ Competition scenario } & \multicolumn{2}{|c|}{ Male } & \multicolumn{2}{|c|}{ Female } \\
\hline Species & Competitor species & $n$ & Pupal weight (mg) & $n$ & Pupal weight (mg) \\
\hline \multirow[t]{6}{*}{ S. inferens (small) } & S. inferens (small) & 9 & $132.67 \pm 5.23^{\mathrm{ab}}$ & 11 & $186.73 \pm 10.22$ \\
\hline & S. inferens (large) & 5 & $126.80 \pm 10.87^{\mathrm{bc}}$ & 13 & $181.62 \pm 9.01$ \\
\hline & S. frugiperda (small) & 2 & $107.50 \pm 4.50^{\mathrm{d}}$ & 3 & $170.67 \pm 31.86$ \\
\hline & S. frugiperda (large) & 5 & $114.40 \pm 8.13^{\mathrm{cd}}$ & 3 & $167.00 \pm 24.58$ \\
\hline & Control & 13 & $150.69 \pm 7.70^{\mathrm{a}}$ & 10 & $206.40 \pm 14.03$ \\
\hline & $P$-value & & 0.019 & & 0.400 \\
\hline \multirow[t]{6}{*}{ S. inferens (large) } & S. inferens (small) & 8 & $131.25 \pm 7.26^{\mathrm{ab}}$ & 11 & $181.73 \pm 8.20$ \\
\hline & S. inferens (large) & 9 & $126.00 \pm 6.45^{\mathrm{bc}}$ & 10 & $181.20 \pm 11.24$ \\
\hline & S. frugiperda (small) & 8 & $108.00 \pm 5.33^{\mathrm{c}}$ & 2 & $204.00 \pm 60.00$ \\
\hline & S. frugiperda (large) & 4 & $109.25 \pm 14.65^{\mathrm{c}}$ & 3 & $169.33 \pm 22.48$ \\
\hline & Control & 8 & $148.75 \pm 9.20^{\mathrm{a}}$ & 12 & $176.17 \pm 8.90$ \\
\hline & $P$-value & & 0.006 & & 0.836 \\
\hline
\end{tabular}

$n$, Total number of pupae recorded. If $P<0.01$, significant at $1 \%$; if $P<0.05$, significant at $5 \%$; if $P>0.05$, non-significant. Means followed by the same letter do not differ by DMRT.

crops which are susceptible to both invasive FAW and native pests is also necessary.

Conflict of interest: The authors declare that they have no conflict of interest.

1. Gao, Y. and Reitz, S. R., Emerging themes in our understanding of species displacements. Annu. Rev. Entomol., 2017, 62, 165183.

2. Reitz, S. R. and Trumble, J. T., Competitive displacement among insects and arachnids. Annu. Rev. Entomol., 2002, 47, 435-465.

3. Williamson, M., Biological Invasions, Chapman and Hall, UK, 1996, p. 244.

4. Sakai, A. K. et al., The population biology of invasive species. Annu. Rev. Ecol. Syst., 2001, 32, 305-332.

5. Vila, M. and Weiner, J., Are invasive plant species better competitors than native plant species? Evidence from pairwise experiments. Oikos, 2004, 105, 229-238.

6. Bruno, J. F., Fridley, J. D., Bromberg, K. D. and Bertness, M. D., Insights into biotic interactions from studies of species invasions. In Species Invasions: Insights into Ecology, Evolution and Biogeography (eds Sax, D. F., Stachowicz, J. J. and Gaines, S. D.), Sinauer, Sunderland, MA, USA, 2005, p. 940.

7. Kfir, R., Competitive displacement of Busseola fusca (Lepidoptera: Noctuidae) by Chilo partellus (Lepidoptera: Pyralidae). Ann. Entomol. Soc. Am., 1997, 90, 619-624.

8. Vargas, R. I., Walsh, W. A. and Nishida, T., Colonization of newly planted coffee fields: dominance of Mediterranean fruit fly over oriental fruit fly (Diptera: Tephritidae). J. Econ. Entomol., 1995, 88, 620-627.

9. Ekesi, S., Billah, M. K., Nderitu, P. W., Rwomushanaiv, I. and Lux, S. A., Evidence for competitive displacement of Ceratitis cosyra by the invasive fruit fly Bactrocera invadens (Diptera: Tephritidae) on mango and mechanisms contributing to the displacement. J. Econ. Entomol., 2009, 102, 981-991.

10. Singh, G. and Jaglan, M. S., Seasonal incidence of different insect-pests in kharif maize. J. Pharmacogn. Phytochem., 2018, 7, 3666-3669.

11. Reddy, Y. V. R. and Trivedi, S., Maize Production Technology, Academic Press, 2008, p. 192.

12. Sharanabasappa, et al., First report of the fall armyworm, Spodoptera frugiperda (J. E. Smith) (Lepidoptera: Noctuidae), an alien invasive pest on maize in India. Pest Manage. Hortic. Ecosyst., 2018, 24, 23-29.

13. Mahadevaswamy, H. M. et al., Prevalence of ' $R$ ' strain and molecular diversity of fall armyworm Spodoptera frugiperda (J. E. Smith) (Lepidoptera: Noctuidae) in India. Indian J. Entomol., 2018, 80(3), 544-553.

14. Guo, J., Zhao, J., He, K., Zhang, F. and Wang, Z., Potential invasion of the crop-devastating insect pest fall armyworm Spodoptera frugiperda to China. Plant Prot., 2018, 44, 1-10.

15. Nagoshi, R. N., Dhanani, I., Asokan, R., Mahadevaswamy, H. M., Kalleshwaraswamy, C. M. and Meagher, R. L., Genetic characterization of fall armyworm infesting South Africa and India indicate recent introduction from a common source population. PLoS ONE, 2019, 14, e0217755.

16. Wu, Q. L., He, L. M., Shen, X. J., Jiang, Y. Y., Liu, J., Hu, G. and $\mathrm{Wu}, \mathrm{K} . \mathrm{M}$., Estimation of the potential infestation area of newlyinvaded fall armyworm Spodoptera frugiperda in the Yangtze river valley of China. Insects, 2019, 10, 298.

17. CABI, Invasive species compendium: Spodoptera frugiperda (fall armyworm), 2020; https://www.cabi.org/ISC/datasheet/29810 (accessed on 10 August 2020).

18. Siddiqui, K. H. and Marwaha, K. K., Pests associated with maize in India. In Vistas of Maize Entomology in India, Kalyani Publishers, Ludhiana, 1994, pp. 3-16.

19. Sekhar, J. C., Rakshit, S., Kumar, P., Anuradha, M. and Dass, S., Differential reaction of CIMMYT maize lines and their hybrid combinations to pink stem borer, Sesamia inferens Walker. Ann. Plant Prot. Sci., 2008, 16, 404-406.

20. Sangi, K. et al., Integrated pest management package for maize. NICPM, New Delhi, 2014, p. 44.

21. Reddy, M. L., Babu, T. R. and Venkatesh, S., A new rating scale for Sesamia inferens (Walker) (Lepidoptera: Noctuidae) damage to maize. Int. J. Trop. Insect Sci., 2003, 23, 293-299.

22. Iqbal, J., Farooq, S. U., Alqarni, A. S., Ali, H., Zeshan, A. and Ansari, M. J., Management of maize stem borer (Chilo partellus) with insecticides of three formulations under field conditions. Indian J. Agric. Sci., 2017, 87, 1720-1724.

23. Baladhiya, H. C., Sisodiya, D. B. and Pathan, N. P., A review on pink stem borer, Sesamia inferens Walker: a threat to cereals. J. Entomol. Zool. Stud., 2018, 6, 1235-1239.

24. Tippannavar, P. S., Talekar, S. C., Mallapur, C. P., Kachapur, R. M., Salakinkop, S. R. and Harlapur, S. I., An outbreak of fall armyworm in Indian subcontinent: a new invasive pest on maize. Maydica, 2019, 64, 10. 
25. Goergen, G., Kumar, P. L., Sankung, S. B., Togola, A. and Tamo, M., First report of outbreaks of the fall armyworm Spodoptera frugiperda (J. E. Smith) (Lepidoptera, Noctuidae), a new alien invasive pest in West and Central Africa. PLoS ONE, 2016, 11, e0165632.

26. Prasanna, B. M., Joseph, E. H., Regina, E., Virginia, M. and Peschke (eds), Fall Armyworm in Africa: A Guide for Integrated Pest Management, CDMX: CIMMYT, Mexico, 2018, pp. 11-28, 1 st edn.

27. Sekhar, J. C., Rakshit, S., Kumar, P., Anuradha, M. and Dass, S., Differential reaction of CIMMYT maize lines and their hybrid combinations to pink stem borer, Sesamia inferens Walker. Ann. Plant Prot. Sci., 2008, 16(2), 404-406.

28. Deole, S., Dubey, V. K., Dash, D. and Gauraha, R., Exploitation of neonate larval behaviour of Sesamia inferens on maize for its effective management. J. Pharmacogn. Phytochem., 2018, 7, 2685-2688.

29. Chapman, J. W., Williams, T., Escribano, A., Caballero, P., Cave, R. D. and Goulson, D., Fitness consequences of cannibalism in the fall armyworm, Spodoptera frugiperda. Behav. Ecol., 1999, 10, 298-303.

30. Chapman, J. W., Williams, T., Escribano, A., Caballero, P., Cave, R. D. and Goulson, D., Age-related cannibalism and horizontal transmission of a nuclear polyhedrosis virus in larval Spodoptera frugiperda. Ecol. Entomol., 1999, 24, 268-275.

31. Balaji, B. N., Gracy, G. R., Shylesha, A. N., Shruthi, G. T. and Nandini, S. N., Status of fall armyworm Spodoptera frugiperda (J. E. Smith) in kharif maize from different districts of Karnataka during 2019. In Proceedings of International Seminar on Transbound. Pest Manage, Tamil Nadu Agricultural University, Coimbatore, 2020, pp. 40-41.

32. Mallapur, C. P., Naik, A. K., Hagari, S., Prabhu, S. T. and Patil, R. K., Status of alien pest fall armyworm, Spodoptera frugiperda (J. E. Smith) on maize in Northern Karnataka. J. Entomol. Zool. Stud., 2018, 6, 432-436.

33. Babu, S. R., Kalyan, R. K., Joshi, S., Balai, C. M., Mahla, M. K. and Rokadia, P., Report of an exotic invasive pest the fall armyworm, Spodoptera frugiperda (J. E. Smith) on maize in southern Rajasthan. J. Entomol. Zool. Stud., 2019, 7, 1296-1300.

34. Chormule, A., Shejawal, N., Sharanabasappa, C. M., Asokan, R., Swamy, H. M. and Studies, Z., First report of the fall armyworm, Spodoptera frugiperda (J. E. Smith) (Lepidoptera, Noctuidae) on sugarcane and other crops from Maharashtra, India. J. Entomol. Zool. Stud., 2019, 7, 114-117.

35. Mahanthi, V. T. R. et al., Report of the invasive fall armyworm, Spodoptera frugiperda (J. E. Smith) (Lepidoptera: Noctuidae) and its natural enemies on maize and other crops from Andhra Pradesh, India. J. Entomol. Zool. Stud., 2019, 7, 1348-1352.

36. Painkra, G. P., Bhagat, P. K., Painkra, K. L., Gupta, S. P., Sinha, S. K., Thakur, D. K. and Lakra, A., A survey on fall armyworm, Spodoptera frugiperda (Lepidoptera: Noctuidae J. E. Smith) in maize crop in Northern hill zone of Chhattisgarh. J. Entomol. Zool. Stud., 2019, 7(6), 632-636.

37. Montezano, D. G. et al., Host plants of Spodoptera frugiperda (Lepidoptera: Noctuidae) in the Americas, Afr. Entomol., 2018, 26(2), 286-300; https://doi.org/10.4001/003.026.0286.

38. Kumar, R. S. and Arivudainambi, S., Prevalence of lepidopteran pests with respect to phenology of hybrid maize. Ann. Plant Soil Res., 2019, 21, 43-47.

39. Arifie, U. et al., Insect pests of maize at different altitudes of North Kashmir, J\&K. J. Entomol. Zool. Stud., 2019, 7, 11231128 .
40. Biradar, S. R., Kotikal, Y. K. and Balikai, R. A., Seasonal incidence of insect pests and their natural enemies on maize. Int. J. Plant Prot., 2011, 4, 402-405.

41. Mallapur, C. P., Manjunath, C., Prabhu, N., Prashant, K. and Balikai, R. A., Incidence and distribution of maize stem borers in farmer's fields of Karnataka State. J. Exp. Zool., 2012, 15, 245249.

42. Manjunath, C., Mallapur, C. P., Goud, K. B. and Patil, R. H., Status of stem borers in major maize growing areas of Karnataka, India. J. Exp. Zool., 2012, 15, 505-511.

43. Bentivenha, J. P., Baldin, E. L., Montezano, D. G., Hunt, T. E. and Paula-Moraes, S. V., Attack and defence movements involved in the interaction of Spodoptera frugiperda and Helicoverpa zea (Lepidoptera: Noctuidae). J. Pest Sci., 2017, 90, 433-445.

44. Chapman, J. W., Williams, T., Escribano, A., Caballero, P., Cave, R. D. and Goulson, D., Age-related cannibalism and horizontal transmission of a nuclear polyhedrosis virus in larval Spodoptera frugiperda. Ecol. Entomol., 1999, 24(3), 268-275.

45. Dial, C. I. and Adler, P. H., Larval behaviour and cannibalism in Heliothis zea (Lepidoptera: Noctuidae). Ann. Entomol. Soc. Am., 1990, 83, 258-263.

46. Carvalho, R. P. L. and Silveira, N. S., Observacoes do comportamento de Spodoptera frugiperda (J. E. Smith, 1797) (Lepidoptera, Noctuidae) ao atacar milho em condicoes de campo. In Resúmen de los trabajos presentados al Prima Congreso Latinoamericano de Entomología. Congreso Latinoamericano de Entomología, Cuzco, Peru, 1971, pp. 92-93.

47. Bentivenha, J. P. F., Baldin, E. L. L., Hunt, T. E., Paula-Moraes, S. V. and Blankenship, E. E., Intraguild competition of three noctuid maize pests. Environ. Entomol., 2016, 45, 999-1008.

48. Bentivenha, J. P., Paula-Moraes, S. V., Baldin, E. L., Specht, A., Da Silva, I. F. and Hunt, T. E., Battle in the new world: Helicoverpa armigera versus Helicoverpa zea (Lepidoptera: Noctuidae). PLoS ONE, 2016, 11, e0167182.

49. Tyagi, M. P. and Sharma, V. K., Biology of pink stemborer, Sesamia inferens Walker on different host plants. Bull. Entomol., 1989, 27, 191.

50. Sharma, H., Jaglan, M. S. and Yadav, S. S., Biology of pink stem borer, Sesamia inferens (Walker) on maize, Zea mays. J. Appl. Nat. Sci., 2017, 9, 1994-2003.

51. Nagarjuna, B., Manjunath, M. and Latha, M., Biology of maize stem borer, Sesamia inferens (Walker) Noctuidae: Lepidoptera. J. Eco-friendly Agric., 2015, 10, 90-91.

52. Sharanabasappa, Kalleshwaraswamy, C. M., Maruthi, M. S. and Pavithra, H. B., Biology of invasive fall armyworm, Spodoptera frugiperda (J. E. Smith) (Lepidoptera: Noctuidae) on maize. 2018, 80(3), 540-543.

53. Polis, G. A., Exploitation competition and the evolution of interference, cannibalism, and intraguild predation in age/size-structured populations. In Size-structured Populations, Springer, Berlin, Germany, 1988, pp. 185-202.

ACKNOWLEDGEMENTS. We thank Dr M. K. Naik, ViceChancellor and Dr M. Hanumathappa, Director of Research, University of Agricultural and Horticultural Sciences, Shivamogga for encouragement and providing the necessary facilities.

Received 10 November 2020; revised accepted 15 January 2021

doi: $10.18520 / \mathrm{cs} / \mathrm{v} 120 / \mathrm{i} 8 / 1358-1367$ 